\title{
Flipped classroom teaching mode in college English education based on constructivism
}

\author{
Huimin Zhao ${ }^{1, \text { a }}$ \\ ${ }^{1}$ Bohai university, Jinzhou, 121013 China \\ ahmzhao2008@163.com
}

Keywords: Flipped classroom; Constructivism; Comprehensive ability

\begin{abstract}
Currently, college English teaching still stays in the traditional teaching mode. The English learning ability as well as the comprehensive application ability of students is very poor. The teaching mode remains still teacher-centered. Based on the constructivism teaching theory, the author investigated the teaching mode of flipped classroom in English teaching. This mode can effectively improve the efficiency of classroom teaching as well as the English comprehensive ability of students.
\end{abstract}

\section{Introduction}

With the deep development of market economy, domestic market calls for high-quality, diversified, integrated and skilful personnel. More and more posts become increasingly strict for employees. They require the employees to have extensive knowledge, strong learning ability, and adaptive capacity, in addition to relevant expertise. Today, the phenomenon of higher education barely meeting market demand becomes increasingly serious. Numerous colleges are identical in the teaching content of undergraduate education. That is, colleges use basically same profession bibliographies for a major while rarely involves capacity development and cultivation of learning ability out of the specialty. In addition, the students cannot get proper training in skill training and capacity building, so that an embarrassing situation occurs that employees have low capacity and even are incompetent in social employment. Therefore, improving students' English comprehensive ability and learning ability becomes the focus of current English education in colleges. On the one hand, students need to be trained with better listening, speaking, reading and writing abilities. On the other hand, they can possess strong learning ability so that they still have strong competitiveness in the occupation after graduating from colleges. At present, English education in colleges has great utility in teaching, because students learn English just for the purpose of taking examinations but not for interests and the improvement of abilities. As a result, teaching is disjointed from learning and students cannot experience joys of studying English. In addition, they study English in class and just for examinations. Students lack of the initiative to learn English and show poor self-learning abilities. The constructivism learning theory can well overcome encountered difficulties in English teaching and improve English teaching efficiency. There are various implementation types in the constructivism learning theory to achieve different teaching objectives, including task teaching, anchored instruction, cognitive apprenticeship and random access instruction ${ }^{[1]}$. College students in China exhibit a low level of motivation for learning English and low classroom teaching efficiency. Aiming at this problem, the authors propose a flipped classroom teaching mode for college English teaching based on constructivism. By doing so, the authors attempt to improve the self-learning ability of students and class efficiency as well as enhance English comprehensive abilities of students.

\section{Constructivism theory and the basic principles of flipped classroom}

Constructivism theory was proposed by Swiss psychologist J. Piaget in the 1960s.[1] Piaget's cognitive theory was developed by studying the interaction between children's cognition and surroundings. Then the theory was developed and perfected by some scholars such as Vygotsky, Ausubel and Bruner to form a set of complete cognitive learning theory. According to constructivism 
theory, instead of being taught by teachers, knowledge is acquired by learners through meaning construction with the help of others by taking advantage of necessary learning materials in certain situation background. The theory recognizes learners' principal roles and suggests that learning activities should be learner-centered, while it affirms teachers' guiding function at the same time. Students are the initiators of learning activities and active constructors of meaning construction, while teachers are the assistants and facilitators in learning activities. Therefore, students have to give their subjective initiative into full play. That is also to say, students should actively collect and analyze relevant materials and information in the meaning construction as well as solve questions in learning. They have to learn cooperatively in the learning process and solve questions encountered in study by communicating and cooperating with learning partners. Constructivism theory emphasizes that students have to have be aware of the contents to learn and prepare for difficult knowledge points before classes. In addition, students should ask teachers for help in class, so that they can actively construct knowledge.[2]

Flipped classroom was first proposed by M. J. Lage et al.,[3] professors at the University of Miami, U.S. Afterwards, it was concrete implemented by J. W. Baker and J. B. Bergmann et al. in teaching. They applied the flipped classroom model in teaching and achieved better teaching effect. Flipped classroom mainly refers to readjust and distribute teaching time in class and extracurricular activities, and transfer the classroom-oriented study to student-oriented one. Students need preview the learning contents before classes, so that teachers need not spend much time repeating the contents. Instead, they spend the majority of the class time communicating with students to solve questions encountered in study together. The extracurricular learning of students is mainly conducted through various means, including watching video lecture, looking up books and reference materials, discussing with other learners. Students autonomously plan their own learning contents and paces, while teachers only prepare courseware and videos for students and collect feedback information of students. Then teachers answer all the questions and communicate with individual students. Flipped classroom changes teacher-centered teaching to student-centered one, so that students can study learning contents more consciously to actively construct knowledge.

\section{Flipped classroom teaching model based on constructivism}

The essence of flipped classroom is to take students as the dominated one and teachers as supporters and change teacher-centered teaching mode in traditional class teaching. The implementation of English flipped classroom can be divided into the following steps: preview before classes, feedback of students, intensive teaching in class, teacher-student interaction, group discussion and extracurricular development. Compared with traditional classroom teaching mode, students under English flipped classroom mode have more time to study autonomously, and are more active in learning knowledge and pondering questions. While teachers take responsible for designing teaching contents and send students videos, courseware and key points of next class through the network in the students' preview stage. In addition, teachers assign preview tasks to students before classes and supervise the preview condition of students so as to highlight key points in classroom teaching.

First, preview before the classes. Preview is the implementation focus of English flipped classroom. Teachers prepare knowledge points for the next class using courseware and videos with concise contents and distinct focuses. For example, teachers make courseware by combining grammar with examples, require students to finish a reading material within a certain time, and produce a listening material into an audio as part of courseware contents. In addition, they send teaching objectives and relevant preview tasks to students and require them to preview the next contents. Students are required to finish the preview tasks assigned by teachers and think relevant questions. Second, students need to feedback their preview results. Before implementing flipped classroom, teachers should check and scores the preview results of students. In addition, the scores are included in the final mark evaluation to urge students to finish the previews before classes effectively. Preview 
of students is basically shown in written forms. That is also to say, students autonomously preview before classes with text contents such as preview notes, solving questions and study notes. In addition, teachers should check the preview report of students and summarize knowledge difficulties fed back from students. Third is the concise lecturing in class. Teachers spend $30 \mathrm{~min}$ lecturing while teacher-student interaction and student-student interaction take the rest $20 \mathrm{~min}$ in each class ${ }^{[4]}$. Teachers should focus on explaining the difficult points for students according to the preview results of students before classes, while skip the knowledge points which have been solved by students. Teachers should have a centralized explanation and practice for related knowledge difficulties including new grammar points, obscure short passages and listening sentences difficult to be comprehended, so as to teach more pointedly. Forth is to conduct teacher-student interactions. In general, the understanding and receiving of students for the contents lectured in class are disparities, so it is necessary to conduct teacher-student and student-student interactions. In addition, teachers should ask students some questions about the lectured questions to check how well they are comprehended by students. For example, teachers can ask students to do sentence-making by using new grammar or conduct oral communication with teachers. By doing so, teachers can check students' mastery degree for knowledge and solve existing problems in time. Group discussion is performed in the fifth step to train students' cooperative learning. Due to the dissimilar understanding and accept abilities of students, group discussion is in favor of the further understanding of knowledge. In addition, students with poor accept abilities are able to further master the learning content through group discussion. In general, a group consists of six students, who cooperatively discuss the questions set by teachers for class discussions and then draw corresponding answers together. After the discussion, the representative of a group is asked to report the results to check the discussion results. Next, teachers judge and mark scores for the learning performances according to the discussion results. Sixth is the extracurricular development. Skill trainings in English need plenty of extracurricular time. While extracurricular development compensates for the shortcoming of limited time of lecturing in classes. Teachers assign relevant tasks to students and let students to finish the tasks in extracurricular time and deepen the understanding of knowledge. The contents of extracurricular development are not limited in the contents lectured in class. For example, teachers require students to read a piece of English web contents or a digest as well as watch an English video or listen to a piece of English listening. Teachers instruct the extracurricular development exercises of students by utilizing the extracurricular time to inspire students' learning interests. The score evaluation of flipped classroom is different from that of the traditional teaching mode. Flipped classroom requires students to be highly involved in, so teachers should directly give the quantitative scores in terms of class participation and performance of students. These scores are used to measure the self-learning effect of students and comprehension of teaching content in classes as well as the task accomplishment of the extracurricular development contents. In contrast, the share of mid-term and final examination scores declines in the final evaluation, which changes the malady that students cram for exams to make students really master knowledge.[4]

Teachers need to apply lots of network multimedia technologies in the implementation of English flipped classroom. Some skill trainings including speaking, writing, reading and listening also need the support of corresponding multimedia hardware. Therefore, the teachers can record short videos of intensive teaching and upload them to shared resources of English learning so that students can download them to study at any time. In addition, the network share contains various learning resources, including listening materials, e-reading materials and practice software for online writing. For classroom instructional design, teaching focuses and difficult points, and so on, teachers should also upload them to the network as shared materials in the form of courseware for the preview of students. Additionally, flipped classroom has extracurricular time for answering questions encountered by students in autonomous learning, and this time is arranged autonomously by teachers. Moreover, the places for answering the questions are not limited in the classes. Teachers can instruct students through some online software, such as network videos and QQ. Teachers can also answer 
questions for students in QQ groups. For the frequent asked questions, teachers provide answers in the group sharing for students to be used for their study.

\section{Conclusions}

The novel English flipped classroom changes teacher-centered mode in traditional classes. It is conducted in the precondition of students' preview and encourages students to study autonomously with the assistance of multimedia network technologies. Thus, the mode greatly increases the autonomous learning time of students' and improves the autonomous learning ability. In addition, teachers should teach briefly and practice effectively in class and have a definite objective in teaching process. Flipped classroom makes students be highly involved in classroom teaching and simulates students' learning interest. Moreover, it changes the malady that students cram for exams and effectively improves students’ English comprehensive ability.

\section{Acknowledgements}

This work is supported by Social Science Foundation of Liaoning Province (No. L15DWW005) and Bohai University Teaching Reform Project (No.BDJG15QNB002).

\section{References}

[1] J. Piaget, The Origin of Intelligence in Children[M[, New York: International University Press. 1966: 84

[2] Mao Xinyong, Application of Constructivism Learning Theory in Teaching[J], Curriculum, Teaching materials, Teaching methods, 1999 (9): 20.

[3] M.J. Lage, G. J. Platt, M. Treglia, Inverting the Classroom: A Gateway to Creating an Inclusive Learning Environment[J] The Journal of Economic Education 31(1): 30 (2000)

[4] G. Mason. Inverting (Flipping) Classrooms - Advantages and Challenges[Z]. 2013. 